\title{
APRENDIENDO A EVALUAR DESDE LAS ARTES PLÁSTICAS EN EL SEGUNDO CICLO DE EDUCACIÓN INFANTIL
}

Learning to evaluate from the visual arts in the second cycle of early childhood education

Aprendendo a avaliar a partir das artes visuais no segundo ciclo da educação pré-escolar

\section{Pilar del Río Fernández (1)}

(1) Profesora Contratada Doctora. Universidad de Málaga, Facultad de Ciencias de la Educación, Málaga, España. Teléfono: 952136656. Correo electrónico: pdelrio@uma.es

\section{Resumen}

En la etapa de Infantil la evaluación ha de usarse como referente para identificar los propios intereses de cada niño y observar las dificultades que tienen, por ello mis alumnos de la Facultad de Ciencias de la Educación en el Grado de Educación Infantil propusieron distintas técnicas de evaluación para poder valorar el aprendizaje artístico de sus alumnos. Se centraron en el segundo ciclo, con niños de 5 a 6 años, y observaron cómo aprendían en su primer acercamiento a las Artes Plástica. Basaron su evaluación en el uso de distintas herramientas, como fueron: el diario, las listas de control, los anecdotarios, etc., que les ayudaban a observar cómo los niños en estas primeras edades eran capaces de adquirir destrezas de aprendizajes tanto artísticas como expresivas, creativas y sociales. Palabras clave: Educación; evaluación; plástica; infantil

\begin{abstract}
In the infantile stage the evaluation has to be used as a reference to identify the own interests of each child and to observe the difficulties that they have, therefore my students of the faculty of Sciences of the education in the degree of infantile education proposed Different evaluation techniques in order to evaluate the artistic learning of their students. They focused on the second cycle, with children ages 5 to 6 , and watched how they learned in their first approach to the plastic arts. They based their evaluation on the use of different tools, such as: The diary, checklists, anecdotes, etc., which helped them to observe how the child in these early ages were able to acquire learning skills both artistic and Expressive, creative and social.
\end{abstract}

Keywords: Education, evaluation, plastic, children

Aprendiendo a evaluar desde las artes plásticas en el segundo ciclo de Educación Infantil 


\section{Resumo}

Na educação pré-escolar a avaliação deve ser usada como referência para identificar os próprios interesses de cada criança e observar as dificuldades que têm. Nesse sentido, os meus alunos da Licenciatura em Educação pré-escolar da faculdade de Ciências de a propuseram diferentes técnicas de avaliação, com o intuito de avaliar a aprendizagem artística dos seus alunos. Eles centraram-seno segundo ciclo, com crianças de 5 a 6 anos, e observaram como aprenderam na sua primeira abordagem às artes visuais. Eles basearam a sua avaliação no uso de diferentes ferramentas, tais como: o diário, listas de verificação, relatório, etc, que os ajudaram a observar como a criança nestas idades precoces eram capazes de adquirir habilidades de aprendizagem, tanto artística como expressivas, criativas e sociais.

Palavras-chave: Educação, avaliação, visual, pré-escolar

\section{Introducción}

En la etapa de Infantil la evaluación ha de usarse como referente para identificar los propios intereses de cada niño y observar las dificultades que tienen, por ello mis alumnos de la Facultad de Ciencias de la Educación en el Grado de Educación Infantil propusieron distintas técnicas para poder valorar el aprendizaje artístico de sus alumnos. Observaron cómo los niños, del Segundo Ciclo de Educación infantil, aprendían en su primer acercamiento a las Artes Plásticas. Practicaron cómo debían evaluar usando herramientas dispares como fueron: el diario, las listas de control, los anecdotarios, etc., Con ellas constataron que los niños aprenden en cualquier situación, tanto formal como informar. Verificaron que las Artes Plásticas son capaces de generar múltiples momentos de aprendizaje pues estimula la creatividad, la imaginación y la adaptación social. Tuvieron siempre presente que la evaluación en estas primeras edades, tiene una función formativa, sin carácter de promoción ni de calificación del alumnado.

\section{Contextualización}

La experiencia que en este trabajo voy a desarrollar se ubica inmersa en una de las principales líneas de actuación que trabajamos en el grupo de investigación HUM816, ésta se fundamenta en el análisis y el estudio del Desarrollo del Currículum Artístico. Es un ejercicio de reflexión ante diversas técnicas de evaluación, elaborado por los alumnos

Aprendiendo a evaluar desde las artes plásticas en el segundo ciclo de Educación Infantil 
del Grado de Maestros de la Universidad de Málaga, tras realizar una serie de proyectos en los que las técnicas plásticas son el eje conductor, con él dejaron constancia de la necesidad de formar maestros imaginativos, capaces de convertir cada proyecto en una aventura de aprendizaje.

Los alumnos implicados en esta práctica pertenecían a la asignatura de Educación en Artes Plásticas y Visuales, del tercer curso que se imparte en Educación Infantil. La clase consta de unos 65 alumnos. Para la elaboración de los proyectos la dividimos en pequeños grupos de 4 o 5 alumnos, los contenidos temáticos fueron seleccionados por cada grupo basándose en los propuestos por el propio currículum. Se trabajaron las texturas, el color, las formas, el retrato y los paisajes. Las reflexiones de cómo evaluarían, partiendo de los ejercicios que ellos propusieron con las distintas técnicas plásticas, basados en el fomento de la creatividad y de la imaginación de los niños en la etapa infantil, constituyen la esencia de este estudio.

\section{Diseño y desarrollo}

Las técnicas de evaluación que se usaron en los distintos proyectos de Artes Plásticas elaborados para los alumnos del Segundo Ciclo de Educación Infantil, fueron:

- El diario: en el cual se anotará los logros obtenidos cada día, por ejemplo se verá si a los niños les ha resultado interesante trabajar con los lápices de colores, o si el día que se trabajaron con las témperas fueron capaces de conseguir distintos colores cuando los mezclaban, también podrían analizar cómo los niños adquieren destrezas en el manejo de instrumentos cuando realizan actividades de collage, esgrafiados, estampados, etc.

- Las listas de control: en las cuales registran la relación de conductas observables en lo que se refiere al manejo de los materiales plásticos, por ejemplo, cómo han distribuido el espacio en las composiciones, la habilidad y precisión que han adquirido en el uso de los lápices, rotuladores o pinceles, a su conocimiento del color, etc.

- Anecdotarios: en ellos el profesor puede apuntar aquellos incidentes, relacionados con las técnicas plásticas y su desarrollo en el aula, que le han parecido más significativos. Debemos dejar constancia de cuando se ha producido y porqué creemos que esto ha ocurrido. Conviene aportar recomendaciones que sirvan para corregir un determinado comportamiento, por ejemplo si los niños secan los pinceles en sus propias camisetas, borran lo dibujado con tanta fuerza que rompen el propio papel, etc.

Aprendiendo a evaluar desde las artes plásticas en el segundo ciclo de Educación Infantil 
- Análisis de producciones de los alumnos: es necesario conservar los trabajos realizados por los alumnos, estos deben de fecharse para controlar perfectamente los progresos de los alumnos. Debe evaluarse el progreso que hace cada niño de mes en mes, atendiendo a la distribución del espacio, el sentido de la forma, la habilidad para controlar los movimientos de las manos y dedos, el desarrollo del sentido del color, de la composición, y en general de su capacidad creativa.

- Entrevistas con los propios alumnos: hemos de saber lo que los alumnos han aprendido realizándoles preguntas, conocer aquello que les ha parecido más interesante en cada proyecto de Artes Plásticas, entender qué es lo que más trabajo les ha costado elaborar, o lo que no les ha interesado.

- Realización de fotografías y vídeos de la propia actividad: es interesante constatar mediante imágenes el interés que cada actividad del proyecto ha ido generando, a menudo el análisis de ellas nos da la posibilidad de poder comentar los avances de nuestros alumnos con el resto del equipo de profesores.

\section{Evaluación y conclusión}

El ejercicio de aprender a evaluar a los niños de Infantil a partir de los propios proyectos docentes con carácter artístico, supuso un interesante análisis de observación y de desarrollo de la actitud crítica. En cada proyecto se trabajaron distintos contenidos propuestos por el Ministerio de Educación y Ciencia para el currículum de Educación Infantil (las formas, los colores, las texturas, el volumen, etc.) todo el conjunto ofrece la posibilidad de que los niños conozcan las distintas técnicas plásticas partiendo de la elaboración de las actividades. Con su realización los niños pueden experimentar descubriendo los elementos que configuran el lenguaje plástico y los profesores evaluarán cómo el niño desarrolla su capacidad expresiva realizando sus primeros dibujos, se acerca intuitivamente al color y disfruta generando texturas, o cómo realiza sus originales retratos, paisajes y dibujos de animales, etc. Se valorará el proceso de aprendizaje y se estudiarán los datos obtenidos con las técnicas de evaluación descritas para tomar decisiones individualizadas.

En líneas generales podemos afirmar que evaluar en el segundo ciclo de Educación Infantil, desde el conocimiento de las Artes Plásticas, es realizar un seguimiento del aprendizaje que ayude a conocer al niño en su dimensión más creativa e imaginativa, teniendo presente su desarrollo madurativo.

Aprendiendo a evaluar desde las artes plásticas en el segundo ciclo de Educación Infantil 


\section{Referencias}

Pellicer Iborra, C. (2017). La evaluación del aprendizaje en educación infantil. Madrid: Anaya.

Martínez, L., \& Gutiérrez, R. (2003). Las artes plásticas y su función en la escuela. Málaga: Aljibe

Real Decreto 1630/2006, de 29 de diciembre, por el que se establecen las enseñanzas mínimas del Segundo Ciclo de Educación Infantil.

Bejarano González, F. (2011). La evaluación en Educación Infantil. Cuadernos de Educación y Desarrollo, 3(29). 